\title{
Monitoring Marine Areas from the International Space Station: the Case of the Submerged Harbor of Amathus
}

\author{
Daniele Cerra $^{1}$, Peter Gege ${ }^{1}$, Evagoras Evagorou ${ }^{2,3}$, Athos Agapiou ${ }^{2,3}$, and Raquel de \\ los Reyes ${ }^{1}$ \\ ${ }^{1}$ German Aerospace Center (DLR), Remote Sensing Technology Institute, \\ Münchnerstr. 20, 82234 Weßling, Germany \\ ${ }^{2}$ Remote Sensing and Geo-Environment Lab, \\ Department of Civil Engineering and Geomatics, Faculty of Engineering and Technology, Cy- \\ prus University of Technology, Saripolou 2-8, Limassol 3036, Cyprus \\ ${ }^{3}$ Eratosthenes Centre of Excellence, Saripolou 2-8, Limassol 3036, Cyprus \\ daniele.cerraedlr.de
}

\begin{abstract}
The submerged harbor of Amathus in Cyprus is a sensitive cultural heritage requiring special attention in the frame of Marine Spatial Planning. The monitoring of water depth in the surrounding area can raise awareness on effects, such as shoreline erosion, which could lead to a deterioration of the relics.

This paper assesses the quality of bathymetric maps around the site derived from the DESIS hyperspectral sensor mounted on the International Space Station. The depth values are compared to products derived from traditional multispectral sensors, and assessed with LiDAR measurements acquired in situ. An imaging spectrometer such as DESIS would be able to derive additional water quality parameter such as phytoplankton concentration, assessing at the same time eutrophication and pollution in this sensitive area.
\end{abstract}

Keywords: Bathymetry, Remote Sensing, Imaging Spectrometry, DESIS, Marine Spatial Planning, Cultural Heritage, Amathus, Cyprus.

\section{Introduction}

Marine Spatial Planning (MSP) is defined in the EU Directive (2014/89/EU) [1] as 'a process by which the relevant Member State's authorities analyze and organize human activities in marine areas to achieve ecological, economic and social objectives [2]. Various local, regional projects and initiatives are currently implemented at a European level. The European MSP platform [3] summarizes these efforts made by several European countries towards the implementation of the Directive. Among other EU MSP projects, a cross-border cooperation program is currently running in Cyprus (more information in [4]), aiming to better coordinate actions regarding the MSP policy.

In general, the MSP goal is to study and plan the use of the coastal and sea space in line with societal goals, values and targets towards future sustainability. The MSP policy is not an easy task, rather a very complex one integrating land (coastal) and sea activities, taking into consideration the problems raised from the interaction of these 
activities, as well as future potentials and opportunities derived from these activities in the given economical and societal context of the country. In order to do this, minimum requirements are needed to identify the interactions of the various activities in the coastal and sea zones, as well as to identify and use available and updated data.

The role of Earth Observation sensors to support MSP policy has been already acknowledged in the past in several studies [5-7]. Satellite sensors are able to provide reliable and up to date information over large areas, covering in the same time land and sea, providing an important informative tool to local stakeholders and other interested parties. Among other activities, the historical and cultural aspects of an area should be taken into consideration during the design and implementation of an MSP policy. The role of Earth Observation sensors for heritage management has been highlighted in [810], providing information regarding the context of a site. A critical aspect of heritage managements refers to sites that are nowadays partially covered by water. Several examples can be found where archaeological sites, once established in the coast, are nowadays partially or fully covered by water due to sea level changes through the millennia $[11,12]$.

The utility of bathymetry maps derived from remote sensing analysis in the field of underwater archaeology is presented in [13] for the EU-funded project ITACA. Results on the prehistoric settlement at Metohi Greece, and analysis of the modern shipwreck Elphis I, place the archaeological sites in a spatial context of the surrounding underwater and surface features, and help in estimating anthropogenic hazards to the site.

In this paper, we study the ancient town of Amathus or Amathous, an important archaeological site situated on the south coast of the island of Cyprus, in close proximity to the modern town of Lemesos (Limassol). During the Archaic period the town acquired special wealth as one of the Kingdoms of Cyprus, and had remarkable commercial relations both with the Aegean and the Syropalestinian coast. The agora, baths and palace on the archaeological site attract a large number of visitors and tourists every year. Of special interest for this paper is the external port of the city, the ruins of which are preserved today under the sea [14].

Due to the proximity of the site to the modern town of Lemesos, as well as its location just a few meters from the coastline, with the ancient harbour now submerged, Amathous requires a special attention in the frame of the MSP implementation. In this paper we aim to showcase how new sensors can support such actions in better understanding the context of an archaeological site, even if this is partially submerged. In contrast to the use of very high resolution multispectral sensors, which have been widely used in the last years in the literature for monitoring archaeological sites [1516], this study uses data acquired from DESIS (DLR Earth Sensing Imaging Spectrometer), a recently launched hyperspectral sensor mounted on the International Space Station (ISS) [17]. An imaging spectrometer measures the reflected solar radiation for a target on ground across narrow and contiguous spectral bands, allowing identifying and characterizing Earth surface materials, such as minerals in rocks and soils, vegetation types and stress indicators, and water constituents.

This paper assesses the quality of bathymetric maps derived from the DESIS sensor around the Amathus Cultural Heritage site. We show how small variations in the water level covering the submerged harbor can be observed, along with spatial and temporal 
changes due to tidal activities and long term phenomena. Such information is important for the management of the site, as changes in the surroundings, such as shoreline erosion, may lead to the deterioration of the relics. The accuracy of the depth values is assessed by comparing them to LiDAR measurements acquired in situ. In addition, bathymetric maps are useful for the better understanding of the topography of the site as a whole, connecting thus the land and sea information; furthermore, these are necessary for shallow and underwater geophysical prospections, such as the application of electric resistivity, which may be carried out in the area in the future. These non-invasive remote sensing technologies can penetrate the seafloor, and indicate geophysical anomalies that can be linked with archaeological proxies.

Finally, the advantages of using an imaging spectrometer with respect to a multispectral sensor are demonstrated by comparing the depth values with bathymetrical maps derived from Sentinel-2 data. This is not the only application for which DESIS can outperform traditional multispectral sensors in coastal environments, of interest for MSP in critical sites such as Amathus: an imaging spectrometer would be able to yield several additional physical parameters, in order to help monitoring both water quality and vegetation and soil characterization in the area. These can greatly improve the characterization of submerged habitat compositions [18], the assessment of water quality [18], and the monitoring of environmental threats. Some examples will be shortly discussed in the conclusions to highlight the value of imaging spectrometry in the frame of MSP.

\section{Batyhmetry Analysis}

\subsection{The DESIS Sensor}

The DESIS sensor was installed on the Multi-User System for Earth Sensing (MUSES) platform of the ISS in 2018, and represents one of the few spaceborne sensors of this kind being operative in the last few years, especially after the decommissioning of the EO-Hyperion sensor on March 2017. Imaging spectrometry, also known as hyperspectral remote sensing, enables the quantification of chemical and physical parameters by a dense sampling of the solar electromagnetic energy reflected by the Earth's surface. DESIS operates in the spectral range from 400 and $1000 \mathrm{~nm}$, with a spectral sampling distance of $2.55 \mathrm{~nm}$ and a Full Width Half Maximum (FWHM) of about $3.5 \mathrm{~nm}$. The ground sampling distance is $30 \mathrm{~m}$ with 1024 pixels across track. For a comprehensive review of the data products, quality and validation of DESIS, the reader is remanded to [17].

Imaging spectroscopy represents a powerful tool for analysis and monitoring of sensitive marine areas, as water quality parameters such as concentration of phytoplankton and suspended matter can be reliably derived, along with bathymetrical maps in coastal areas, which are accurate up to a water depth in which the light reflected at sea floor is still detectable at the surface. The DESIS sensor can derive such parameters more accurately than multispectral sensors characterized by broad spectral bands with large gaps between them, with a decrease in spatial resolution as tradeoff. Nevertheless, the hindrances posed by the decrease in ground sampling distance can be mitigated by the 
use of spectral unmixing techniques, which allow performing analysis at sub-pixel level for specific applications such as target detection and constituents mapping.

\subsection{Dataset}

The ISS flies on a non-sun-synchronous orbit, with an inclination of $51.6^{\circ}$ from west to east, approximately $400 \mathrm{~km}$ above the Earth surface. In the case of the island of Cyprus, around 40 acquisitions per year are possible with a sun elevation angle of $30^{\circ}$ or larger, with acquisition possibilities well distributed along the year [20]. This number increases when taking into account the MUSES/DESIS tilting capabilities of $40^{\circ}$.

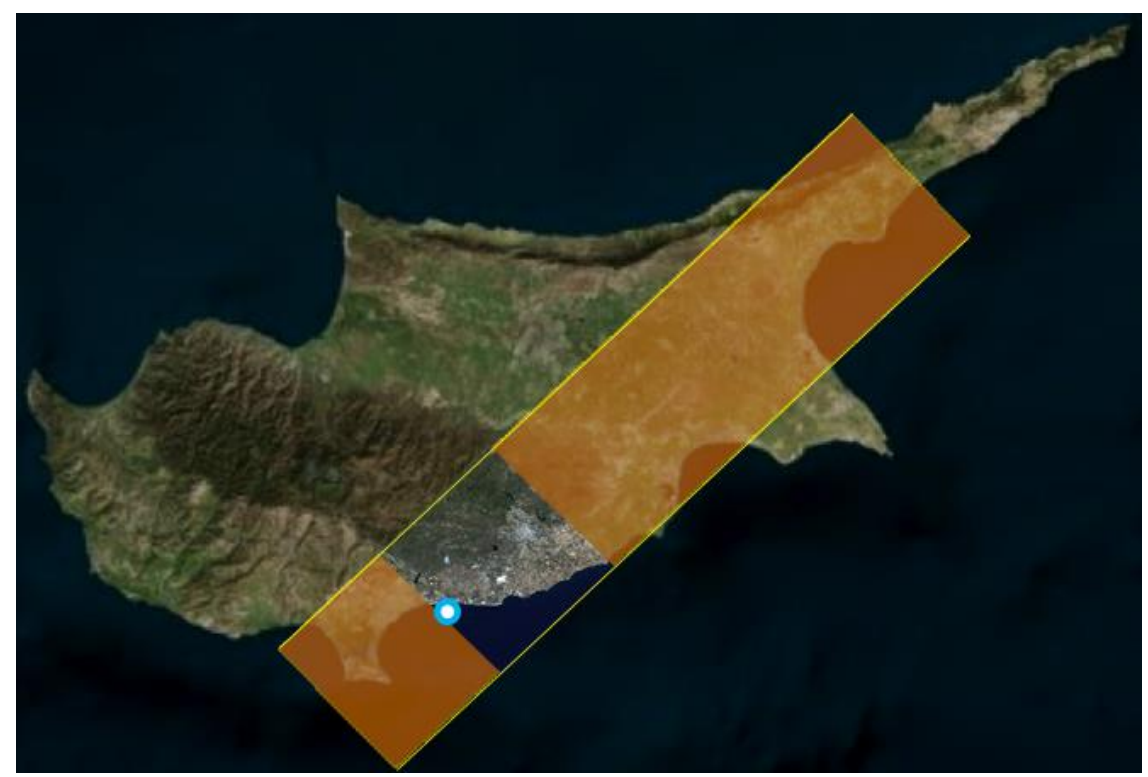

Fig. 1. Footprint of DESIS acquisition over the southern coast of Cyprus ( $9^{\text {th }}$ of June 2020), covering most of the island's southern coast. A sample DESIS quicklook depicted as a true color combination for a single tile including the Amathus harbor is overlaid. The location of the submerged harbor is indicated by a blue circle.

Given the inclined orbit of the ISS, a single DESIS acquisition, having an approximate width of $30 \mathrm{~km}$, can cover most of the southern coast of Cyprus with a single pass (Fig. 1). In this paper, we analyse a DESIS image acquired over the southern coast of Cyprus on the $9^{\text {th }}$ of June 2020 at 8:28 am local time. The image is acquired in rolling shutter mode, which acquires the spectral bands sequentially. The resulting spatial and spectral shifts in the acquisitions are compensated in the DESIS DLR ground segment processing chain, along with the usual geometric, radiometric and spectral corrections. The final output is in Bottom-of-atmosphere reflectance, corresponding to a Level 2A product.

A subset of the strip in Fig. 1 is analyzed. In the figure, the location of the submerged Amathus harbor is shown. A quicklook for a single DESIS tile is overlaid on the image 
in a true color combination (R: band 24 at $636 \mathrm{~nm}, \mathrm{G}$ : band 16 at $554 \mathrm{~nm}, \mathrm{~B}$ : band 8 at $472 \mathrm{~nm}$ ). The derived bathymetrical maps are compared to the ones generated from Sentinel-2 data. For this multispectral sensor, a cloud-free acquisition from the $13^{\text {th }}$ of June 2017 is used, in the same period of the year as the DESIS acquisition. Validation is performed using a set of official water depth records.

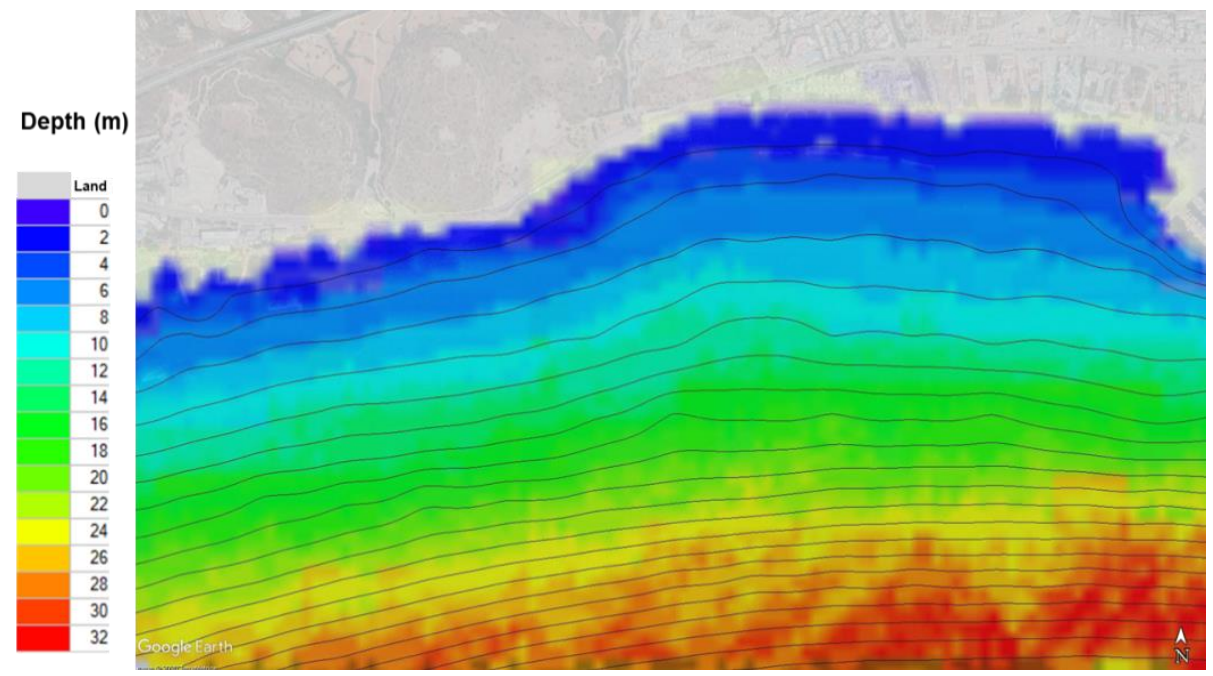

Fig. 2. Batyhmetrical map on the Amathus harbor area, derived from DESIS data, with overlaid contour lines of depth values measured in situ, depicted in black. The contour lines are spaced 2 meters and are used to assess the results. Pixels depicted with the same color have a depth within a range of 2 meters. For depths up to approximately 15 meters, the estimated depth matches well the contour lines. The map is overlaid on an archive image on the site (Google Earth, () 2020 Maxar Technologies).

\subsection{DESIS-derived bathymetry}

We used the 2D module [21] of the WAter color SImulator WASI [21,23] for processing the DESIS data. WASI is a Windows-based software that is available free of charge [24]. By applying inverse modeling to the measured reflectance spectra, the water depth was derived for each DESIS pixel together with two further parameters that were assumed to vary across the image, i.e. the brightness of sand and the reflections at the water surface. The underlying algorithm is a physically based, so-called bio-optical model for shallow waters of Albert $[25,26]$. The reflectance of the sea floor was approximated using an albedo spectrum of sand from the WASI data base, which was measured at the Baltic Sea. The reflections at the water surface were simulated using the three-component model of Gege [27] for the sky radiance that is reflected in the viewing direction. This model also compensates to some extent for errors from atmospheric correction. Because inverse modeling of DESIS pixels in adjacent deep water areas indicated very low concentrations of water constituents, the model parameters for 
the concentrations of phytoplankton, total suspended matter and colored dissolved organic matter were set to zero.

The derived water depths are validated by comparison with depth measurements carried out by the Department of Land Surveyors of Cyprus (DLS), the country's official cartographic provider. The dataset covers water depths up to $50 \mathrm{~m}$ and was collected in three phases, in 2012, 2014 and in 2018 using multi-beam echo sounders and airborne LiDAR. The horizontal and vertical accuracy of the data is $\pm 0.1 \mathrm{~m}$ and $\pm 0.5 \mathrm{~m}$, respectively.

Fig. 2 shows the bathymetrical map with the contour lines for water depth overlaid. The depth map has been mapped to a false color image in discrete intervals, with a color change indicating an increase in depth of $2 \mathrm{~m}$. This depth interval is the same spacing the contour lines in the overlaid reference data.

A detail reported in Fig. 3 on the Amathus harbor area shows how the subtle variations around the harbor are captured by the DESIS-derived bathymetric map, which are smoothed out in the depth contour lines of the reference data set. This indicates that accurate maps could be obtained on the site, and the variations in depth accurately monitored, helping the management of the site by continuously observing long term phenomena such as shoreline erosion and changes in tidal effects. The DESIS-derived bathymetric map is shown in Fig. 4 for a larger area including the Amathus harbor site.

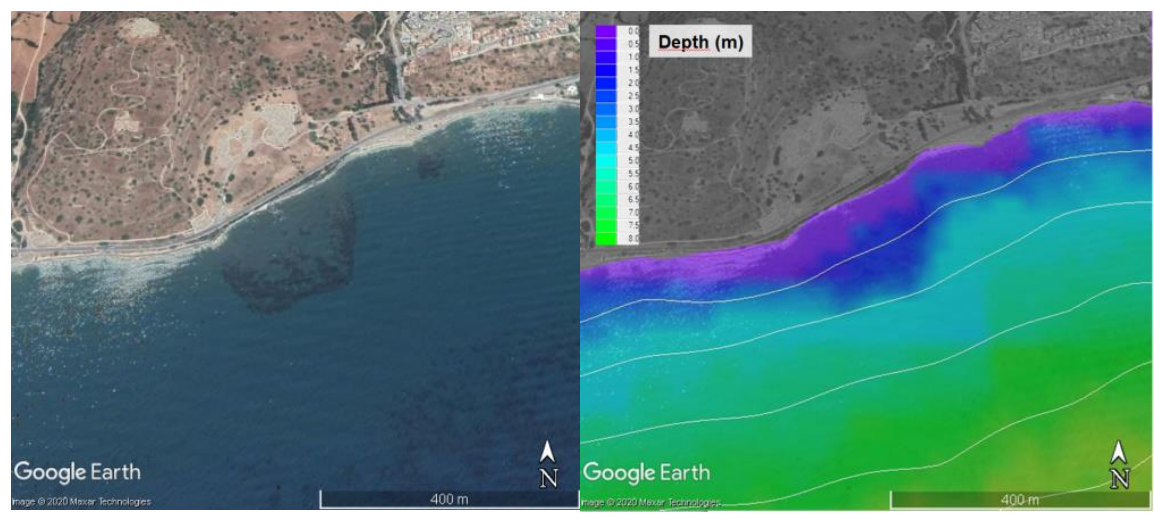

Fig. 3. Left: The submerged Amathus harbor, visible under water close to the coastline, and surroundings (Google Earth, (C) 2020 Maxar Technologies). Right: comparison of contour lines derived from in situ measurements and overlaid bathymetric map derived from DESIS data. Local variations around the harbor are lost in the contour lines.

As illustrative validation, a scatter plot comparing estimated and reference depth values is reported in Fig. 5. The locations of the points used for the validation are reported as circles in Fig. 4. In total, 37 points could be used for this purpose. 


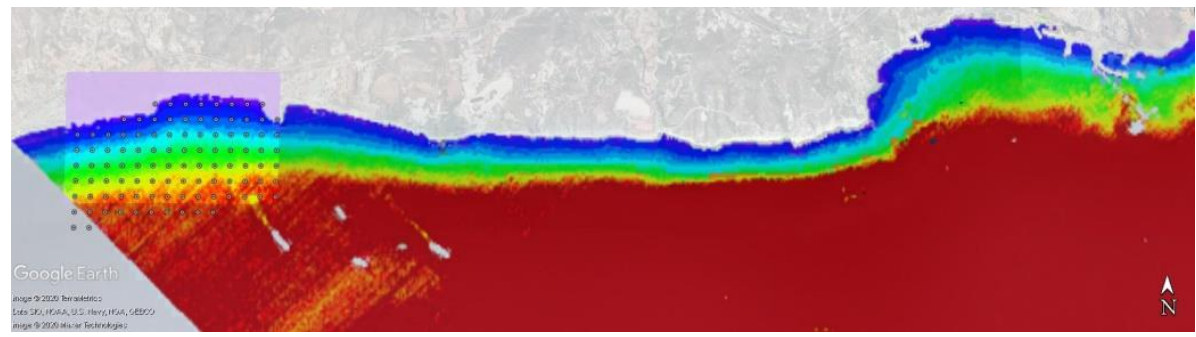

Fig. 4. Estimated depth values for a subset of the image depicted in Fig. 1 including the Amathus harbor. The black dots represent the locations of points where LiDAR depth measurements have been collected, which are used to assess the accuracy of the results (see Table 1 and

Fig. 5). The area reported in Fig. 2 is highlighted on the left side of the image (ref. legend therein). The map is overlaid on an archive image on the site (Google Earth, (C) 2020 Maxar Technologies).

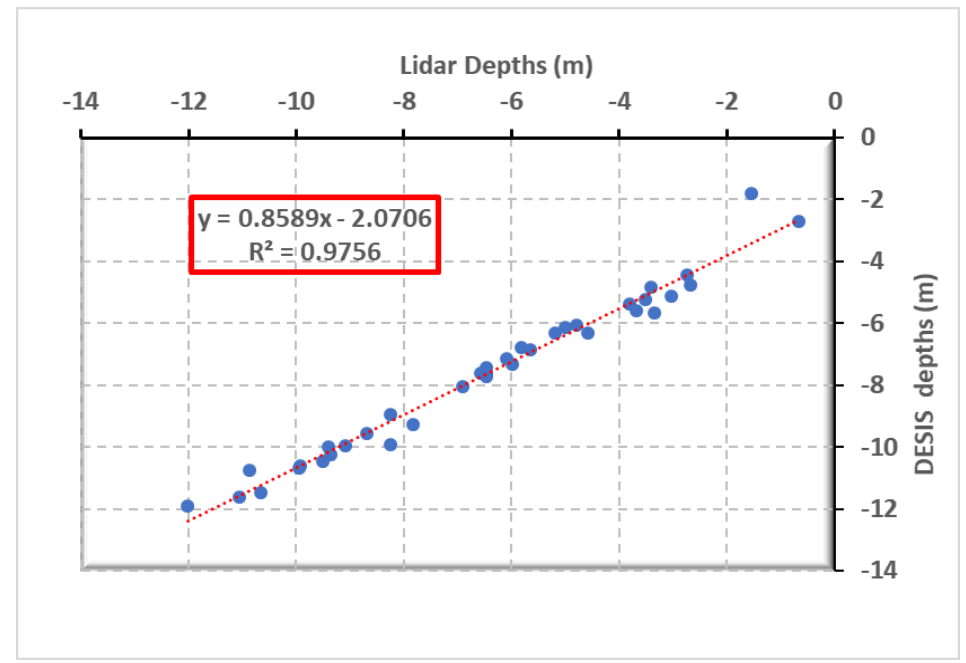

Fig. 5. Scatter plot of 37 depth values as measured in situ with LiDAR instruments vs. values estimated from spaceborne DESIS data, up to a depth of 12 meters.

The plot confirms the reliability of the derived map, showing that the depth values derived from DESIS match very well the measured depth values in the area of interest.

\subsection{Comparison with Sentinel-2 Analysis}

In order to further compare the bathymetrical results of DESIS, we rely on a recent work by Evagorou et al. [28] which performs a multi-temporal analysis in the wider area of Amathus using the Sentinel-2 sensor. More specifically, we use a bathymetrical map derived by applying the ratio transform algorithm on a Sentinel-2 image of Level 2A which includes radiometric, geometric, cloud masking, and atmospheric 
corrections, obtained through the Copernicus Hub, with a sensing period of the 13th of June 2017.

An offset and scaling were then applied using different factors to the two depth maps in order to find a best fit to the measured values, regarded as ground truth. Both sets of values fit the measured depths very well, with a correlation index $\left(\mathrm{R}^{2}\right)$ above 0.96 for the depth ranging from 0 to 12 meters. The figure of merit for the comparison is the Root Mean Squared Error, defined as

$$
\operatorname{RMSE}(X, Y)=\sqrt{\frac{\sum_{i}\left(x_{i}-y_{i}\right)^{2}}{N}},(1)
$$

where $x_{i}$ and $y_{i}$ represent the $i$-th estimated and reference depth value present in both data collections, respectively, and $N$ the total number of comparable points. Results are summarized in Table 1.

Table 1. Comparison between depth values derived from DESIS and Sentinel-2 for the depth range from 0 to 12 meters. The RMSE is computed with respect to the reported number of validation points available in the area, measured in situ with LiDAR instruments.

\begin{tabular}{c|ccc|} 
Sensor & Date & RMSE $(\mathrm{m})$ & $\mathrm{R}^{2}$ \\
\hline DESIS & $09 / 06 / 2020$ & $\mathbf{0 , 4 1}$ & $\mathbf{0 , 9 8}$ \\
Sentinel-2 & $13 / 06 / 2017$ & 0,72 & 0,96 \\
\cline { 2 - 4 }
\end{tabular}

The comparison of DESIS and Sentinel-2 shows that the former can produce more accurate bathymetrical results, in spite of the worse ground sampling distance characterizing the sensor (30 m of DESIS against $10 \mathrm{~m}$ of Sentinel-2). An RMSE value of $0.41 \mathrm{~m}$ was estimated for DESIS, resulting in an approximate twofold increase in accuracy with respect to Sentinel-2.

\section{Conclusions}

In this paper we assessed the capabilities of the DESIS imaging spectrometer mounted on the ISS to derive accurate bathymetric maps: the area of interest are the shallow waters in which the submerged harbor of Amathus lies, just outside the southern coast of the Cyprus area nearby Limassol. Results show that the bathymetric maps derived from the DESIS imaging spectrometer are quite accurate, with a Root Mean Squared Error below half a meter with respect to a series of approximately 40 points measured in situ with LiDAR instruments. The error approximately doubles when using instead traditional satellite data characterized by a higher spatial resolution and broader spectral bands, such as Sentinel-2.

The use of imaging spectrometer data on the site goes well beyond the production of bathymetric maps. The frequent possible acquisitions of the DESIS sensor can be 
employed to derive water quality parameters such as turbidity, and suspended and dissolved water constituents such as chlorophyll-a and Colored Dissolved Organic Matter (CDOM). In turn, these can help in estimating the phytoplankton concentration and assess eutrophication and pollution in this sensitive area.

Furthermore, the sensor would be optimal to map the distribution of Mediterranean seagrass meadows, such as the Posidonia Oceanica which is abundant in this area, and protected by legislation, among other conventions, also under the EU Habitat Directive (92/43/CEE). This will be included in our future analysis on the site. At the same time, relevant soil and vegetation parameters could be derived for the emerged lands in a single acquisition, yielding a complete picture on the surroundings and the context of a site of interest. This highlights the important role that remote sensing can play in the frame of MSP, as this technology provides frequent, inexpensive and accurate information on large areas.

\section{Acknowledgements}

The authors would like to acknowledge the 'ECXELSIOR' H2020 Teaming project (www.excelsior2020.eu). This paper is under the auspices of the activities of the 'ERATOSTHENES: Excellence Research Centre for Earth Surveillance and SpaceBased Monitoring of the Environment'-'EXCELSIOR' project that has received funding from the European Union's Horizon 2020 research and innovation programme under Grant Agreement No. 857510 and from the Government of the Republic of Cyprus through the Directorate General for the European Programmes, Coordination, and Development.

Part of this research was supported by the project entitled: "Cross-Border Cooperation for Implementation of Maritime Spatial Planning" referred as "THAL-CHOR 2" (" $\Theta \mathrm{A} \Lambda$-X $\Omega \mathrm{P} 2$ " in Greek) and co-funded by the European Regional Development Fund (ERDF), under the Cross-Border Cooperation Programme "INTERREG V-A GreeceCyprus 2014-2020". Also, acknowledgements are given to Department of the Land Survey of Cyprus, for providing soundings of bathymetry.

\section{References}

1. Directive 2014/89/EU of the European Parliament and of the Council of 23 July 2014, "Establishing a Framework for Maritime Spatial Planning”. Available online: http://eur-lex.europa.eu/legal-content/EN/TXT/?uri=uriserv:OJ.L_2014.257.01.0135.01.ENG MSP Project Cyprus, https://www.msp-platform.eu/projects/cross-border-cooperation-maritime-spatialplanning-development (accessed on 11th of Sep. 2020).

2. MSP Platform, https://www.msp-platform.eu/msp-eu/introduction-msp (accessed on 11th of Sep. 2020).

3. MSP Projects, https://www.msp-platform.eu/msp-practice/msp-projects (accessed on 11th of Sep. 2020)

4. MSP Project Cyprus, https://www.msp-platform.eu/projects/cross-border-cooperation-maritime-spatial-planning-development (accessed on 11th of Sep. 2020). 
5. Valentini, E.; Filipponi, F.; Nguyen Xuan, A.; Passarelli, F.M.; Taramelli, A. Earth Observation for Maritime Spatial Planning: Measuring, Observing and Modeling Marine Environment to Assess Potential Aquaculture Sites. Sustainability 2016, 8, 519.

6. Ouellette, W., Getinet, W., Remote sensing for Marine Spatial Planning and Integrated Coastal Areas Management: Achievements, challenges, opportunities and future prospects, Remote Sensing Applications: Society and Environment, Volume 4, 2016, Pages 138-157, ISSN 2352-9385, https://doi.org/10.1016/j.rsase.2016.07.003.

7. Hadjimitsis, D., Agapiou, A., Themistocleous, K., Mettas, C., Evagorou, E., Soulis, G., Xagoraris, Z., Pilikou, M., Aliouris, K., \& Ioannou, N. (2016). Maritime Spatial Planning in Cyprus, Open Geosciences, 8(1), 653-661. doi: https://doi.org/10.1515/geo-2016-0061.

8. Agapiou A., Lysandrou V., Hadjimitsis D.G., 2017, The Cyprus coastal heritage landscapes within Marine Spatial Planning process, Journal of Cultural Heritage, 23, 28-36, http://dx.doi.org/10.1016/j.culher.2016.02.01.

9. Agapiou, A.; Lysandrou, V.; Hadjimitsis, D.G. Earth Observation Contribution to Cultural Heritage Disaster Risk Management: Case Study of Eastern Mediterranean Open Air Archaeological Monuments and Sites. Remote Sens. 2020, 12, 1330.

10. Cerra, D.; Plank, S.; Lysandrou, V.; Tian, J. Cultural Heritage Sites in Danger-Towards Automatic Damage Detection from Space. Remote Sens. 2016, 8, 781.

11. Mogstad, A.A.; Ødegård, Ø.; Nornes, S.M.; Ludvigsen, M.; Johnsen, G.; Sørensen, A.J.; Berge, J. Mapping the Historical Shipwreck Figaro in the High Arctic Using Underwater Sensor-Carrying Robots. Remote Sens. 2020, 12, 997.

12. Guyot, A.; Lennon, M.; Thomas, N.; Gueguen, S.; Petit, T.; Lorho, T.; Cassen, S.; HubertMoy, L. Airborne Hyperspectral Imaging for Submerged Archaeological Mapping in Shallow Water Environments. Remote Sens. 2019, 11, 2237.

13. Guzinski, R., Spondylis, E., Michalis, M., Tusa, S., Brancato, G., Minno, L., \& Hansen, L. (2016). Exploring the Utility of Bathymetry Maps Derived With Multispectral Satellite Observations in the Field of Underwater Archaeology, Open Archaeology, 2(1). doi: https://doi.org/10.1515/opar-2016-0018

14. Amathous, Department of Antiquities (accessed on 11th of Sept. 2020), http://www.mcw.gov.cy/mcw/DA/DA.nsf/All/D20ED526826AB796C225719B00374A92

15. Masini, N.; Lasaponara, R. Sensing the Past from Space: Approaches to Site Detection. In Sensing the Past. From Artifact to Historical Site; Masini, N., Soldovieri, F., Eds.; Springer: Dordrecht, The Netherlands, 2017; pp. 23-60.

16. Luo, L.; Wang, X.; Guo, H.; Lasaponara, R.; Zong, X.; Masini, N.; Wang, G.; Shi, P.; Khatteli, H.; Fulong, C.; et al. Airborne and spaceborne remote sensing for archaeological and cultural heritage applications: A review of the century (1907-2017). Remote Sens. Environ. 2019, 232, 111280

17. Alonso, K.; Bachmann, M.; Burch, K.; Carmona, E.; Cerra, D.; de los Reyes, R.; Dietrich, D.; Heiden, U.; Hölderlin, A.; Ickes, J.; Knodt, U.; Krutz, D.; Lester, H.; Müller, R.; Pagnutti, M.; Reinartz, P.; Richter, R.; Ryan, R.; Sebastian, I.; Tegler, M. Data Products, Quality and Validation of the DLR Earth Sensing Imaging Spectrometer (DESIS). Sensors 2019, 19, 4471.

18. Pinnel, N. A Method for Mapping Submerged Macrophytes in Lakes Using Hyperspectral Remote Sensing. Ph.D. Thesis, Technische Universität München, München, Germany, 2007.

19. Hestir, E.L.; Brando, V.E.; Bresciani, M.; Giardino, C.; Matta, E.; Villa, P.; Dekker, A.G. Measuring freshwater aquatic ecosystems: The need for a hyperspectral global mapping satellite mission. Remote Sens. Environ. 2015, 167, 181-195. 
20. Huemmrich, F., Campbell, P., Gao, B., Flanagan, B., Goulden, M., 2017. ISS as a Platform for Optical Remote Sensing of Ecosystem Carbon Fluxes: A Case Study Using HICO. IEEE Journal of Selected Topics in Applied Earth Observations and Remote Sensing. PP. 1-16. 10.1109/JSTARS.2017.2725825.

21. Gege, P. WASI-2D: A software tool for regionally optimized analysis of imaging spectrometer data from deep and shallow waters. Computers \& Geosciences, 2014, 62, 208-215. http://dx.doi.org/10.1016/j.cageo.2013.07.022.

22. Gege, P. The water colour simulator WASI: An integrating software tool for analysis and simulation of optical in-situ spectra. Computers \& Geosciences, 2004, 30, 523-532.

23. Gege, P., Albert, A. A tool for inverse modeling of spectral measurements in deep and shallow waters. In: L.L. Richardson and E.F. LeDrew (Eds): "Remote Sensing of Aquatic Coastal Ecosystem Processes: Science and Management Applications", Kluwer book series: Remote Sensing and Digital Image Processing, 2006, Springer, ISBN 1-4020-3967-0, pp. 81-109.

24. Gege, P. WASI (Water Colour Simulator). 2020. Available online: http://www.ioccg.org/data/software.html (accessed on 24 Sept 2020).

25. Albert, A., Mobley, C.D., 2003. An analytical model for subsurface irradiance and remote sensing reflectance in deep and shallow case-2 waters. Optics Express 11, 28732890.

26. Albert, A. Inversion Technique for Optical Remote Sensing in Shallow Water, Ph.D. Thesis, University of Hamburg, Hamburg, Germany, 2004.

27. Gege, P. Analytic model for the direct and diffuse components of downwelling spectral irradiance in water. Appl. Opt. 2012, 51, 1407-1419, doi:10.1364/AO.51.001407.

28. Evagorou, E., Mettas, C., Agapiou, A., Themistocleous, K. and Hadjimitsis, D.: Bathymetric maps from multi-temporal analysis of Sentinel-2 data: The case study of Limassol, Cyprus, Adv. Geosci., 45(1988), 397-407, doi:10.5194/adgeo-45-397-2019, 2019. 